\title{
The Optimal Model of Refugee Crisis Based on the Shortest Time
}

\section{Chang'an Wang ${ }^{1, a}$ Xiaoqian Liu $^{2, b}$}

${ }^{1}$ School of West Center for Economic Research, Southwestern University of Finance And Economics, Chengdu 611130,China

${ }^{2}$ School of Management, Sichuan Agricultural University, Chengdu 611130, China

aWangtcjy@163.com, bwptaq1123@163.com

\section{Keywords: Refugee Crisis; Genetic Algorithm; Optimization Evacuation Model}

\begin{abstract}
European refugee crisis, which began in 2015, has become a serious problem in Europe. In order to measure the crisis, an optimization evacuation model is established to address this problem. Considering total possible refugees needed to be evacuated in the shortest time, Genetic Algorithm is used to find the optimal solution through MATLAB. Based on the data of EU refugee crisis, specially choosing Iraq and Syria, the road resistant coefficient, refugees' satisfaction and other factors are added in our model. The optimal movement by the consideration of six travel routes mentioned in the problem is simulated, the result is fairly consistent with the realistic.
\end{abstract}

\section{Introduction}

European refugee crisis, which began in 2015, has become a serious problem in Europe. There have been tens of millions of migrants that come from the Middle East pouring into Europe, now facing the second, but the most severe refugee wave which is rather complex, tremendous, and accompanied with frequent humanitarian disasters. Refugees were those who fled for fears of violence against political and social conflict of their country, the vast majority of which fled by sea from Middle East to European and Asia areas ,but some of the left made their way out through Mediterranean to some countries like Turkey, Hungary, Germany, France and Britan.

Up to now, European refugee crisis is not optimistic. On one hand, there are surge in the number of refugees, most of which were displaced and homeless and even lost their lives in the flight path. On the other hand, European countries are now facing economic crisis. With uncertain increasing number of refugees in the future, domestic resources may not be able to meet the needs of the refugees. Besides, there are serious different policies between EU countries on how to deal with the refugee problems. As far as we can see, EU countries attempt to handle the crisis problem through prevention, military operations as well as quota system. But it is the core issue about how to digestive the increase number of refugees with providing the necessary humanitarian aid. Multi-objective evacuation plan that minimizes the total evacuation time, the total path length and congestion level was put forward $^{[1]}$ (Stepanov and Smith, 2009). In addition, certain targets ,such as minimize the average evacuation time, maximize the evacuees and minimize the number of survival congestion level of join point of Roads have been put forward ${ }^{[2]}$ (Badler, 2006). At present, some optimization algorithms or technologies, such as game theory,intelligent agentnon-dominated genetic algorithm based on fast classification NSGA-II ${ }^{[3]}$ (Sinuany-stem Z,1993).Benders' Separate settlement method, linear programming relaxation theory and cellular automation have been tried to solve the path optimization problem in evacuation.

\section{Basic Assumptions}

Assumptions. Iraq and Syria have been chosen for the reason that they both broke out wars during 
that time. Considering the reality and the need of modeling, assumption are made as follows:

I. Each country is a node and the distance between two countries is the distance between the two nodes. That is to say, we ignore the actual road conditions and just use the abstract of nodes to measure the distance.

II. The number of moving refugees is a constant during the process of migration. We assume that to make it workable of our optimization model.

III. We do not consider the resource constraints like steamship traffic during the migration processes. This means the transportation resources are efficient.

IV. The capacity per transportation is a fixed value between two countries.

Justification of our Assumptions. Refugees' optional migration routes may be different, but as they become deserters, it is reasonable to suppose that they just have the most basic means of transportation oreven worse. On the other side, although the capacity of transportation may not be a constant as the time goes by, concern such capacity on averaged, this parameter can be regarded as constants.

\section{Models}

The Model of Measuring the Refugee Crisis. Static analysis method is employed in the first basis model to study the major crises such as refugee crisis. As far as concerned, the highest priority of refugee crisis is to ensure them arrive their destination in the shortest time. This goal can reduce the uncertainty like refugee resettlement, infectious diseases, and the death rate of refugee and so on.

The Evacuation Decision-Making Model. An evacuation decision model is formed to analyze the refugee crisis. Then the shortest time is defined as the objective function of the merit function. The aim is to find the best solution to evacuation of refugees, which including the best staff assignments and the best selection of optimal path.

As the notion defined in the early page, the $o$ represents the country of refugees, that is the country should be evaluation. The $p$ represents the immigrant-accepting country, that is the destination of the refugee evacuation. The decision-making model of evacuation M1 is

$$
\min \sum_{o \in D} \sum_{p \in E} T_{o p}(1)
$$

Which subject to

$$
\begin{aligned}
& T_{o p}=\frac{Q_{o p}}{\sum_{m \in M} Q_{m o p} \times C_{m}} \times \frac{D_{o p}}{V_{o p}} \times\left(1+r_{o p}\right) \\
& \forall O \in D, \forall p \in E \\
& \sum_{o \in D} Q_{o p} \leq Q_{p} \times \rho_{p}-Q_{p}^{o}, \quad \forall p \in E \\
& \sum_{p \in E} Q_{o p}=Q_{0}^{*}
\end{aligned}
$$

In the merit functions,(1) is the objective function, $D$ represent the collection of the refugee countries, $|\mathrm{D}|=\mathrm{n} ; E$ represent the collection of the refugee countries, $|\mathrm{E}|=\mathrm{m}, m, n \in N$, where $N$ represents the set of negative integer; $T_{o p}$ represents the time that refugees should take into from refugee countries $o$ to their destination $p$,the time unit is second. 
The function (2) (4) are the condition of constraint. $T_{\text {op }}$ is the value of the time, determined by the number of evacuation, evacuation capacity, evacuation speed and the road resistance coefficient. As it is know, transportation is a core factor in major hazards disaster, because it may hinder evacuation of the refugees. To incarnate transportation factor, road resistance coefficient $r_{o p}$ is added into (2). If the larger the value of $r_{o p}$ is, the more severe, the resistance of the road is. The value range of $r_{o p}$ is $0 \leq r_{o p} \leq \infty Q_{o p}$ is the number of people from the refugee country $o$ to the immigrant-accepting countries $p, Q_{o p} \in N Q_{0}^{*}$ represent the overall amount of the refugees, $Q_{0}^{*} \in N$. $M$ represent the set of available transportation in refugee evaluation. $Q_{\text {mop }}$ represent the number of the $m$ section type of vehicles; $D_{o p}$ is the distance from $o$ to $p ; V_{o p}$ is the averaged velocity from $o$ to $p_{;} r_{o p}$ is the road resistance coefficient from $o$ to $p$.

The Assumptions of the Model. The policies of the immigrant-accepting countries are not changed in the giving period. the impact on the evacuation capability of national resources is ignored.

Analyze of the Model. During the process of evacuation, $Q_{m o p}$ and $C_{m}$ show the evacuation resources between two points. To simplify model, $Q_{\text {mop }}$ and $C_{m}$ are combined and are replace by the size of the evacuation capability $\left(C_{o p}\right) . C_{o p}$ indicates the capabilities from $o$ to $p$.

$$
C_{o p}=\sum_{m \in M} Q_{m o p} \times C_{m}
$$

$D_{o p}, V_{o p}$ and $r_{o p}$ indicate the difficulty of evacuation. Use $C h_{o p}$ to represents

such difficulty of evacuation

$$
C h_{o p}=\frac{D_{o p}}{V_{o p}} \times\left(1+r_{o p}\right)
$$

The aim of our analysis is to fine the best evacuation strategy through the M1model. The equivalent target function is defined as

$$
\min \sum_{o \in D} \sum_{p \in E} \frac{Q_{o p} \times C h_{o p}}{C_{o p}}
$$

Which subject to

$$
\begin{gathered}
\sum_{o \in D} Q_{o p} \leq Q_{p} \times \rho_{p}-Q_{p}^{0}, \quad \forall p \in E \\
\sum Q_{o p}=Q_{o}^{*}, \quad \forall o \in D \\
X_{o p}=0,1, \quad \forall o \in D, \quad \forall p \in E
\end{gathered}
$$


Sensitivity Evaluation of the Model. After formulating the optimization function, the next important job is how to fine its solution. Here choose GA to handle it. According to figures given by the related websites and through the analysis by mathematical , three variables were chosen.

In Table1, the number of refugees is summarized in the country or territory of asylum. Absolute and relative values are determined for each host country for which all the data used in computing parameters was available. As it is known, for each host country, there existing differences among numerous factors, such as food, water, shelter and healthcare which determined disparate capacity. A great capacity will appeal to many refugees. Therefore, the number of refugees is representative of every host country's capacity in our model.

Table1: the capacity of the country

\begin{tabular}{|l|l|l|l|}
\hline Country & $\begin{array}{l}\text { The Ratio of Refugees } \\
\text { to 1,000 inhabitants }\end{array}$ & $\begin{array}{l}\text { The Population of Host } \\
\text { Country in 2015(ten } \\
\text { thousand) }\end{array}$ & $\begin{array}{l}\text { The number of Refugees } \\
\text { (ten thousand) }\end{array}$ \\
\hline Switzer Land & 8.45 & 801.4 & 6.77 \\
\hline Turkey & 23.72 & 7584 & 179.89 \\
\hline Austria & 7.13 & 803.29 & 5.73 \\
\hline Germany & 3.1 & 8039.93 & 24.92 \\
\hline Italy & 1.57 & 6111 & 9.59 \\
\hline Netherlands & 4.89 & 1678.9 & 8.21 \\
\hline Norway & 9.14 & 506.37 & 4.63 \\
\hline Sweden & 14.66 & 955.59 & 14.01 \\
\hline United Kingdom & 1.82 & 6349 & 11.56 \\
\hline Bulgaria & & & 1.13 \\
\hline Denmark & 1.53 & 736.46 & 1.76 \\
\hline France & 3.15 & 558.04 & 26.7 \\
\hline Montenegro & 4.13 & 6464 & 0.62 \\
\hline
\end{tabular}

(data from: http://www.unhcr.org/statistics/mid2015stats.zip)

According to actual situation, The transport velocity is 14 25 nautical mile per hour by sea and 150 200 kilometers per hour by rail. The suppose capacity of vehicle is 800 person. Suppose that the $r_{o p}=0$,which is an ideal condition. The optimal options by selecting the Syria and Iraq are simulated as the representative countries of refugees while the Germany, Turkey and another eleven countries represent the immigrant-accepting countries. Here is the value of the parameters:

$$
\rho_{p}=1, r_{o p}=0 \forall o \in D, \forall p \in E
$$

$\bar{Q}_{0}=\left\{Q_{p}, p \in E\right\}$

$=\left(67700,1798900,57300,249200,95900,82100, \quad \bar{Q}_{0}=\left\{Q_{o p}, o \in D, p \in E\right\}=(1943881,85279)\right.$

$46300,140100,115600,11300,17600,267000,6200)$ 


$$
\begin{aligned}
& C h=\left[C h_{o p}\right]_{2 \times 13} \\
& =\left(\begin{array}{cccccccc}
105.2 & 24 & 87.9 & 105.5 & 91.4 & 118 \\
126.1 & 41.2 & 109 & 126.6 & 112.5 & 139.1 & \\
138.6 & 138.9 & 145.5 & 53.8 & 122.4 & 117.8 & 72.9 \\
159.7 & 159.9 & 166.5 & 74.9 & 130 & 120 & 80
\end{array}\right)
\end{aligned}
$$

In order to fine the solution more efficient, Hexadecimal coding schemes and De Jong's (1975) model are used to dispose the parameters. The gatoolbox are used in MATLAB to solve the problem.

Table 2: the number of the refugees through different routes

\begin{tabular}{|r|r|r|r|r|r|}
\hline & $\begin{array}{r}\text { C } \\
\text { H }\end{array}$ & TR & AT & $\begin{array}{r}\text { D } \\
\text { Y }\end{array}$ & IT \\
\hline I & 0 & 177940 & 573 & 0 & 95 \\
RQ & & 0 & 00 & & 900 \\
\hline & S & BG & DK & F & M \\
\hline S & 0 & 11300 & 0 & 0 & 0 \\
Y & & & & R & 0 \\
\hline I & 0 & 0 & 0 & 5 & 62 \\
RQ & & & & 9560 & 00 \\
\hline
\end{tabular}

(Notice: The other results is all zero)

\section{The Results}

As can be seen from the table, the majority of the refugees choose Turkey, which means Eastern Mediterranean is the most popular road. It is fairly agree with the reality. To be more specific, the number of Syria refugees that each road should takes is as follows: 1779400to Turkey, 57300to Austria, 95900to Italy, 11300 to Bulgaria; the number of Iraq refugees that each road should take are the same is reflected in the table.

Then the conclusion is that Turkey should open two entry points while the other countries just open one entry. As can be seen, the individuals themselves determine the satisfaction in the constraint condition; the six travel routes that they must take mainly attribute to the defined time; the transportation types affect the passenger carrying capacity and the transport speed, which then affect the defined time finally. And the capacity of the country limits the refugee population. Both of all above are reflected as parameters in the optimization model.

Furthermore, based on the predicting number of the possible refugees in the metrics that have been established, a country can determine the number of entry points or the type of them to meet their needs.

\section{Sensitivity Evaluation of the Model}

Choose the road resistance coefficient as the sensitivity analysis parameter for the evacuation decision model. 
Sensitivity Evaluation of the Model. Firstly, the change of the road to Turkeys is considered. We know that when the

$r_{o p}=0$, it is the basic situation in our analysis. Here set the $r_{o 2}=0$, while the other parameters stay the same. That is

$$
\begin{aligned}
& \bar{r}=\left\{r_{o p}, o \in D, p \in E\right\} \\
& =(0,1,0,0,0,0,0,0,0,0,0)
\end{aligned}
$$

The result is showed by the table 3

Table 3: the number of the refugees through different routes

\begin{tabular}{|l|c|c|c|c|c|}
\hline & CH & TR & AT & DE & IT \\
\hline SY & 0 & 1798900 & 50495 & 0 & 87939 \\
\hline IRQ & 0 & 0 & 6805 & 0 & 7961 \\
\hline & SE & BG & DK & FR & MNE \\
\hline SY & 0 & 6547 & 0 & 0 & 0 \\
\hline IRQ & 0 & 4752 & 0 & 59560 & 6200 \\
\hline
\end{tabular}

As can be seen from the table3, when the road resistance coefficient increase by a time, the amount of refugees decrease by nineteen people. If the road resistance coefficient increase gradually, there will be less refugees choose this road.

Compare with the Reality. Comparing it with the situation that $r_{o p}=0$ with the situation in reality.

As it is know, in reality, the road resistant coefficient of different country is different. So the road resistant coefficient is reseted as follow:

$$
\begin{aligned}
& \bar{r}=\left\{r_{o p}, o \in D, p \in E\right\} \\
& =(3,1,3,4,2.5,7.5,6,2,6,4.5,4)
\end{aligned}
$$

Here is the result:

Table 4: the number of the refugees through different routes

\begin{tabular}{|c|c|c|c|c|c|}
\hline & CH & TR & AT & DE & IT \\
\hline SY & 59560 & 1713621 & 57300 & 0 & 95900 \\
\hline IRQ & 0 & 85279 & 0 & 0 & 0 \\
\hline & SE & BG & DK & FR & MNE \\
\hline SY & 0 & 11300 & 0 & 0 & 6200 \\
\hline IRQ & 0 & 0 & 0 & 0 & 0 \\
\hline
\end{tabular}

It shows that although the road to Turkey, the Eastern Mediterranean is still the most popular road. 


\section{Conclusions}

To sum up, The optimal model to evacuate the European refugee crisis at the shortest time, taking Iraq and Syria as instances, have been worked out. The first aspect taken into major consideration is the shortest defined time to evaluate refugees. The changes of parameters can have an impact on the quantity of refugees and the country which they flee to, Mathematical modeling is used to solve optimization route choice. It can be used to deal with actual problems in the refugees crisis, which provides a way to help refugees to reach safe country in the shortest time.

\section{References}

[1] Stepanov A,MacGregor Smith J. Multi-objective evacuation routing in transportation networks.European Journal of Operational Research,2009.198(2):435-446

[2] Nuria P,Norman B.Modeling Crowd and Trained Leader Behavior during Building Evacuation.IEEE Computer Graphics and Applications,2006,26(6):80-86

[3] Sinuany-Stern Z, Stern E. Simulating the evacuation of a small city: the effects of traffic factors.Socio-Economic Planning Sciences,1993.27(2):97-108 